\title{
Effects of reduced platelet count on the prognosis for patients with non-small cell lung cancer treated with EGFR-TKI: a retrospective study
}

\author{
$\mathrm{Lu} \mathrm{Xu}^{1 \dagger}$, Fangzhou $\mathrm{Xu}^{1 \dagger}$, Haobo Kong ${ }^{1}$, Meiling Zhao ${ }^{1}$, Yuanzi Ye ${ }^{2^{*}}$ (1) and Yanbei Zhang ${ }^{1 *}$ (D)
}

\begin{abstract}
Background: Progressive lung cancer is associated with abnormal coagulation. Platelets play a vital part in evading immune surveillance and angiogenesis in the case of tumor metastasis. The study aimed to analyze the predictive and prognostic effects of platelet count on non-small cell lung cancer (NSCLC) patients treated with epidermal growth factor receptor tyrosine kinase inhibitors (EGFR-TKIs).

Methods: This study retrospectively analyzed the prognostic effects of platelets on 52 NSCLC patients with epidermal growth factor receptor (EGFR) mutant following EGFR-TKI treatment. Related data, together with the progression-free survival (PFS) and overall survival (OS) were collected before and after 2 cycles of treatments (60 days).
\end{abstract}

Results: The anti-EGFR treatment markedly reduced the platelet count in 33 (63.5\%) patients after 2 cycles of treatment. Multivariate Cox analysis revealed that, the decreased platelet count was closely correlated with the longer OS (HR $=0.293$; 95\%Cl: 0.107-0.799; $p=0.017$ ). Besides, the median OS was 326 days in the decreased platelet count group and 241 days in the increased platelet count group ( $\mathrm{HR}=0.311 ; 95 \% \mathrm{Cl}$ : $0.118-0.818 ; P=0.018)$, as obtained from the independent baseline platelet levels and other clinical features.

Conclusions: The platelet count may predict the prognosis for EGFR-TKI treatment without additional costs. Besides, changes in platelet count may serve as a meaningful parameter to establish the prognostic model for NSCLC patients receiving anti-EGFR targeted therapy.

Keywords: Platelet, EGFR-TKl, Non-small cell lung cancer, Progression-free survival, Overall survival

\footnotetext{
*Correspondence: yeyuanzi@hotmail.com; zhangyanbei1963@126.com

${ }^{+}$Lu Xu and Fangzhou Xu contributed equally to this work.

${ }^{2}$ Department of Pathology, the First Affiliated Hospital of Anhui Medical University, Hefei, Anhui 230022, People's Republic of China

'Department of Geriatric Respiratory and Critical Care, Anhui Geriatric Institute, the First Affiliated Hospital of Anhui Medical University, Hefei, Anhui 230022, People's Republic of China
}

(c) The Author(s). 2020 Open Access This article is licensed under a Creative Commons Attribution 4.0 International License, which permits use, sharing, adaptation, distribution and reproduction in any medium or format, as long as you give appropriate credit to the original author(s) and the source, provide a link to the Creative Commons licence, and indicate if changes were made. The images or other third party material in this article are included in the article's Creative Commons licence, unless indicated otherwise in a credit line to the material. If material is not included in the article's Creative Commons licence and your intended use is not permitted by statutory regulation or exceeds the permitted use, you will need to obtain permission directly from the copyright holder. To view a copy of this licence, visit http://creativecommons.org/licenses/by/4.0/ The Creative Commons Public Domain Dedication waiver (http://creativecommons.org/publicdomain/zero/1.0/) applies to the data made available in this article, unless otherwise stated in a credit line to the data. 


\section{Background}

Advanced cancer is frequently accompanied with overt or subclinical thrombosis, which is manifested as thromboembolism (TE), especially for venous thromboembolism (VTE), including deep vein thrombosis (DVT) and pulmonary embolism (PE) [1]. Under the control of mutated epidermal growth factor receptor (EGFR), renin-angiotensin system (RAS), methionine (MET) or other tumorigenic pathways, vascular endothelial growth factor (VEGF) and other mediators are over-expressed in lung cancer patients. This thereby induces the growth of exuberant blood vessels, the remarkable remodeling of vascular walls, the activation of coagulation system inside or outside the vascular lumen, and high incidence of intracavity occlusive thrombus [2].

Activated coagulation may also take place in the form of bleeding or mixed disorder like disseminated intravascular coagulation (DIC), or the more subtle subclinical laboratory changes (such as the elevated fibrin d-dimer levels, the prolonged prothrombin time, and the markedly reduced platelet count) [3]. TE is usually observed in adenocarcinoma patients at the time of diagnosing the cancer, whereas DIC is often detected at the advanced cancer stage that is associated with a short survival time. The frequency of TE may be underestimated, and the radiological characteristics of TE rarely present when diagnosing cancer patients with DIC or those at the terminal stage [4].

As the small discoid anuclear cell fragments, platelets exert key parts in hemostasis, which represents a frontline physiological response to acute tissue injury. Vascular disruption triggers the localized deposition of platelets, as well as the release and activation of platelet granular ingredients. In addition, the platelet-released molecules (PRMs) can further recruit and activate platelets, resulting in multi-cellular aggregates and restricting blood loss. The activated coagulation cascades jointly lead to thrombin generation, which thereby consolidates the increased thrombus through further promoting platelet activation and catalyzing fibrin formation [5].

Accumulated evidence demonstrates that, the development of lung cancer is closely correlated with the platelet-induced thrombus, which is considered as a candidate cancer biomarker. Platelets can be activated through the direct interactions between cancer cells, or via the indirect mediators released by cancer cells. In turn, the activated platelets invoke the phenotypic transformation of cancer cells by means of metastasis and angiogenesis [6]. On the other hand, thrombus formation is also involved in some oncogenic mutated genes, including the the protein-coding genes (such as EGFR, RAS) and non-coding RNA (microRNA). A series of gene mutations regulate multiple effectors in the coagulation system, like tissue factors, protease activated receptors (PAR-1 and PAR-2), coagulation factors (FII and FVII), as well as platelet function and fibrinolysis mediators $[7,8]$.

The platelet count is frequently regarded as one part of the routine laboratory tests, which can be utilized to predict thrombosis without inducing any additional costs. This study aimed to assay the predictive and prognostic effects of changes in platelet count on non-small cell lung cancer (NSCLC) patients receiving anti-EGFR targeted therapy, and to determine the anti-cancer efficacy of EGFR tyrosine kinase inhibitors (TKIs).

\section{Methods}

\section{Patient enrollment}

From March 2016 to March 2019, a total of 52 patients with advanced or recurrent NSCLC and EGFR mutations treated with EGFR-TKI at the First Affiliated Hospital of Anhui Medical University were retrospectively analyzed in this study. The criteria for the use of antiEGFR therapy were as follows: (1) deletion in exon 19 $(n=23)$; (2) substitution in exon $21(n=14)$; (3) amplification of EGFR gene $(n=3)$; and (4) the remaining patients were qualified for treatment in the past era when there was no obligation to indicate the EGFR gene mutation status. In addition, patients with active infection, systemic corticosteroids, or haematological malignancy were excluded, since these conditions might affect the test values of hematological laboratory markers.

\section{Data collection}

The following variables were extracted, including platelet count, D-dimer concentration, age, gender, clinical stage, histological diagnosis, smoking, EGFR mutation, other therapies (like thoracic surgery, chemotherapy, radiofrequency ablation, and radiotherapy), concomitant diseases (like cerebral infarction, arterial hypertension, diabetes mellitus, heart disease, chronic obstructive pulmonary disease), and the choice of TKIs (such as gefitinib, erlotinib, ectinib, or ositinib). Besides, routine assessments of complete blood count and coagulogram (including the platelet concentration, D-dimer concentration) were carried out before and after 2 cycles of therapy (first effective evaluation after 60 days of treatment). All clinical data were utilized for evaluating the therapeutic efficacy in combination with the chest Computed Tomography (CT) scan results in accordance with the Response Evaluation Criteria in Solid Tumors (RECIST, version 1.1). The primary endpoint was PFS calculated from the date of TKI initiation to the documented disease progression or death of any cause. OS was defined as the duration between the initiation of EGFR-TKI treatment and the date of death due to any cause. 


\section{Statistical analysis}

SPSS 22.0 statistical software package (SPSS Inc., Chicago, Illinois, USA) was adopted for data analysis. The abnormally distributed continuous parameters were expressed as median and quartiles. The platelet count after 2 cycles of treatment was compared to that with no treatment through the Wilcoxon's test. Chi-square test was used to compare the correlation between different variables and patient prognosis. Univariate Cox regression analysis was applied to identify prognostic variables. Then, significant variables were incorporated into the multivariate Cox regression analysis to analyze independent influencing factors. Meanwhile, the survival curves were plotted according to the Kaplan-Meier method and log-rank test. A two-sided $P$-value of $<0.05$ was deemed as statistically significant.

\section{Results}

\section{Patients' characteristics}

A total of 52 advanced or recurrent NSCLC patients with common EGFR mutation were treated by EGFRTKIs during the study period. Table 1 presents the detailed patient characteristics. There were 26 (50\%) males and $26(50 \%)$ females in the total cohort, with the median age of 62.5 years (Quartiles, 50.3-69). Besides, 82.9\% patients were treated with chemotherapy, $6.4 \%$ with radiofrequency ablation, $4.3 \%$ with radiotherapy, $4.3 \%$ with thoracic surgery, and $2.1 \%$ with radioactive seed implantation. Of these patients, 14 had arterial hypertension, 9 had diabetes mellitus, 3 had heart disease, 3 had chronic obstructive pulmonary disease, and 3 had cerebral infarction. Additionally, 17 of these 52 cases had a history of smoking. The two-cycle TKI treatment resulted in the markedly reduced platelet count $(n=33$, 63.5\%), D-dimer content $(n=37,71.2 \%)$. Table 1 .

\section{Evaluation of blood indicators in patients before and after treatment}

Table 2 displays the detailed characteristics of platelet count and D-dimer content. After the two-cycle TKI treatment, the platelet count $(p=0.026)$ and D-dimer content $(p=0.007)$ were markedly reduced compared with those in non-treatment.

Afterwards, patients were classified as the increase and decrease groups according to the blood indicator values. In the platelet decrease group, the median platelet count before treatment $(248 ; 192-335)$ was higher than that after treatment $(211 ; 159-233.5)(P<0.001)$. For patients in the platelet increase group, the median platelet count was 172(133-225) before treatment and 211 (159-276) after anti-EGFR treatment, which was markedly increased $(P<0.001)$. Among patients in the D-dimer decrease group, the median D-dimer level after TKI treatment $(0.42 ; 0.245-1.145)$ was evidently decreased
Table 1 Patients' characteristics

\begin{tabular}{|c|c|c|}
\hline Variables & $\mathbf{N}$ & $\%$ \\
\hline \multicolumn{3}{|l|}{ Age } \\
\hline Median & 62.5 & \\
\hline Quartiles & $50.3-69$ & \\
\hline \multicolumn{3}{|l|}{ Gender } \\
\hline Female VS Male & $26: 26$ & 50: 50 \\
\hline \multicolumn{3}{|l|}{ Clinical stage } \\
\hline III B VS IV & $3: 49$ & 5.8: 94.2 \\
\hline \multicolumn{3}{|l|}{ Histological diagnosis } \\
\hline Adenocarcinoma VS Others & $51: 1$ & 98.1: 1.9 \\
\hline \multicolumn{3}{|l|}{ Anti-EGFR therapy } \\
\hline Gefitinib & 34 & 65.4 \\
\hline Erlotinib & 7 & 13.5 \\
\hline Ectinib & 9 & 17.3 \\
\hline Ositinib & 2 & 3.8 \\
\hline \multicolumn{3}{|l|}{ Other treatments } \\
\hline Thoracic surgery & 2 & 4.3 \\
\hline Radiotherapy & 2 & 4.3 \\
\hline Chemotherapy & 39 & 82.9 \\
\hline Radiofrequency ablation & 3 & 6.4 \\
\hline Radioactive seed implantation & 1 & 2.1 \\
\hline \multicolumn{3}{|l|}{ Concomitant diseases } \\
\hline Arterial hypertension & 14 & 43.7 \\
\hline Diabetes mellitus & 9 & 28.1 \\
\hline Heart disease & 3 & 9.4 \\
\hline Chronic obstructive pulmonary disease & 3 & 9.4 \\
\hline Cerebral infarction & 3 & 9.4 \\
\hline \multicolumn{3}{|l|}{ Smoking } \\
\hline Past/current & 17 & 32.7 \\
\hline Never & 35 & 67.3 \\
\hline \multicolumn{3}{|l|}{ D-dimer content } \\
\hline Decrease VS Increase & $37: 15$ & 71.2: 28.8 \\
\hline \multicolumn{3}{|l|}{ Platelet count } \\
\hline Decrease VS Increase & 33: 19 & $63.5: 36.5$ \\
\hline
\end{tabular}

compared with that before treatment (1.48;0.53-3.24) $(P<0.001)$. Similarly, patients in the D-dimer increase group had remarkably increased $D$-dimer levels $(P=$ 0.001). Table 2.

\section{Comparison of prognostic factors within groups}

Patients were divided into the PFS $(+)$ group and the PFS (-) group according to whether they had progressed. Patients were divided into OS (+) and OS (-) groups according to whether they died or not.

Chi-square analysis results (Table 3 ) show that there is no difference between PFS (-) and PFS (+) for each 
Table 2 The detailed characteristics of platelet count and D-dimer content during the first two-cycle treatment

\begin{tabular}{|c|c|c|c|c|c|}
\hline Values & $\mathrm{N}$ & Before Treatment & After Treatment & Statistic(Z) & $P$-value \\
\hline Platelet count & 52 & & & & \\
\hline Median & & 230 & 211 & -2.222 & 0.026 \\
\hline Quartiles & & $172-281.8$ & $159.75-236.5$ & & \\
\hline Decrease group & 33 & & & & \\
\hline Median & & 248 & 211 & -5.012 & 0.000 \\
\hline Quartiles & & $192-335$ & $159-233.5$ & & \\
\hline Increase group & 19 & & & & \\
\hline Median & & 172 & 211 & -3.726 & 0.000 \\
\hline Quartiles & & $133-225$ & $159-276$ & & \\
\hline D-dimer content & 52 & & & & \\
\hline Median & & 0.94 & 0.725 & -2.687 & 0.007 \\
\hline Quartiles & & $0.53-2.72$ & $0.31-1.415$ & & \\
\hline Decrease group & 37 & & & & \\
\hline Median & & 1.48 & 0.42 & -5.303 & 0.000 \\
\hline Quartiles & & $0.53-3.24$ & $0.245-1.145$ & & \\
\hline Increase group & 15 & & & & \\
\hline Median & & 0.88 & 1.22 & -3.408 & 0.001 \\
\hline 1Quartiles & & $0.47-0.95$ & $1.00-2.09$ & & \\
\hline
\end{tabular}

In our laboratory, $125-350\left({ }^{*} 10^{9} / \mathrm{L}\right)$ is adopted as the cut-off value for normal platelet; $<0.5 \mu \mathrm{g} / \mathrm{ml}$ is used as the cut-off value for normal D-dimer

indicator $(P>0.05)$. Moreover, results of Chi-square analysis (Table 4) indicated that, changes in platelet count before and after treatment were different in OS $(-)$ and OS $(+)(P<0.05)$. Similarly, gender, smoking and the presence of other diseases were also statistically significant in both groups $(P<0.05)$. Tables 3 and 4 .

\section{Prognostic factors in patients treated with EGFR-TKI}

As shown in Table 5, no variables were associated with PFS in patients receiving EGFR-TKI, as shown in Table 3.

As shown in Table 6, Variables with $P<0.05$ in univariate analysis were included in multivariate analysis. Multivariate Cox analysis revealed that patients with decreased platelet count $(\mathrm{HR}=0.293$; 95\%CI: $0.107-0.799$; $p=0.017)$, and male $(\mathrm{HR}=0.195 ; 95 \% \mathrm{CI}: 0.042-0.914$; $p=0.038$ ) had longer OS. And the presence or absence of smoking and other diseases had no significant effect on survival. Tables 5 and 6.

\section{Survival analysis}

A total of 52 patients were observed during the followup period, and the median OS among decrease group of platelet was 326 (211.5-614) days. And, the OS values were observed in increase group, with the median OS of 241 (117-517) days. The OS was remarkably extended in patients with decreased platelet count (Fig. 1). The difference in overall survival between the two groups was statistically significant $(P<0.05)$. Figure 1 shows the proportions of patients with no progression at various time points between the platelet decrease and increase groups.

In the meantime, the OS values were observed in male patients, with the median OS of 305.5 (103.5-641.25) days. Male Patients had a longer OS (Fig. 2). Figure 2 shows the survival rates of male patients and female patients at different time points.

\section{Discussion}

In recent years, the more advanced anticancer therapy has been applied in clinical practice thanks to the development of modern oncology, including the advances in genetics, genomics and proteomics. This results in the development of three types of oncologic biomarkers, namely, the predictive, prognostic and early response biomarkers [9]. To search for the appropriate anticancer treatment, some NSCLC patients harboring various genetic mutations have been enrolled for investigation and assay [10]. Recent studies indicate that, paraneoplastic thrombocytosis may serve as a factor to predict the dismal prognosis for lung cancer [11, 12]. As suggested by our results, the platelet count was the most potent differentiating factor for OS (Tables 4 and 6), and EGFRTKI treatment induced the remarkably reduced platelet count among NSCLC patients (Tables 1 and 2). 
Table 3 The difference of prognostic factors between PFS (-) group and PFS(+) group

\begin{tabular}{|c|c|c|c|c|}
\hline Values & PFS (-) & PFS (+) & Statistic $\left(x^{2}\right)$ & $P$-value \\
\hline $\mathrm{N}$ & 5 & 47 & & \\
\hline Platelet & & & 0.653 & 0.390 \\
\hline Increase & $1(20 \%)$ & 18(38.3\%) & & \\
\hline Decrease & $4(80 \%)$ & $29(61.7 \%)$ & & \\
\hline D-dimer & & & 0.211 & 0.549 \\
\hline Increase & $1(20 \%)$ & 14(29.8\%) & & \\
\hline Decrease & $4(80 \%)$ & $33(70.2 \%)$ & & \\
\hline Gender & & & 0.221 & 0.500 \\
\hline Male & $2(40 \%)$ & 24(51.1\%) & & \\
\hline Female & $3(60 \%)$ & 23(48.9\%) & & \\
\hline Age & & & 0.221 & 0.500 \\
\hline$\geq 62.5$ & $2(40 \%)$ & $24(51.1 \%)$ & & \\
\hline$<62.5$ & $3(60 \%)$ & 23(48.9\%) & & \\
\hline Smoking & & & 0.405 & 0.467 \\
\hline Past/current & $4(80 \%)$ & $31(66.0 \%)$ & & \\
\hline Never & $1(20 \%)$ & 16(34.0\%) & & \\
\hline Exon21 & & & 2.038 & 0.153 \\
\hline No & $5(100 \%)$ & $33(70.2 \%)$ & & \\
\hline Yes & $0(0 \%)$ & 14(29.8\%) & & \\
\hline Exon 19 & & & 4.387 & 0.059 \\
\hline No & $5(100 \%)$ & 24(51.1\%) & & \\
\hline Yes & $0(0 \%)$ & 23(48.9\%) & & \\
\hline Other diseases & & & 3.457 & 0.077 \\
\hline No & $5(100 \%)$ & $27(57.4 \%)$ & & \\
\hline Yes & $0(0 \%)$ & $20(42.6 \%)$ & & \\
\hline \multicolumn{5}{|l|}{ Other treatment } \\
\hline No & $1(20 \%)$ & 19(40.4\%) & 0.797 & 0.354 \\
\hline Yes & $4(80 \%)$ & $28(59.6 \%)$ & & \\
\hline
\end{tabular}

PFS progression-free survival, PFS (+) progression group, PFS (-) No-progression group

Consistent with previous trial data on osimertinib which showed high efficacy over 1st and 2nd generation EGFR-TKI [13] yet is associated with decrease in platelet count [14].

Patients with advanced lung cancer may confront more risks related to the thromboembolic complications [1]. In addition, it is suggested in the international clinical practice guidelines that, primary antithrombotic prophylaxis, should be taken into consideration for patients with locally advanced or metastatic lung cancer that receive chemotherapy [15]. According to recent studies, the oncogenic events in cancer cells (such as the expression of mutant K-ras, EGFR) lead to the increased TF levels and activity, which thereby promoting tumor aggressiveness, angiogenesis, and hypercoagulability.
Table 4 The difference of prognostic factors between OS (-) group and OS (+) group

\begin{tabular}{|c|c|c|c|c|}
\hline Values & OS (-) & OS (+) & Statistic $\left(x^{2}\right)$ & $P$-value \\
\hline $\mathrm{N}$ & 34 & 18 & & \\
\hline Platelet & & & 4.294 & 0.039 \\
\hline Increase & $9(26.5 \%)$ & 10(55.6\%) & & \\
\hline Decrease & $25(73.5 \%)$ & $8(44.4 \%)$ & & \\
\hline D-dimer & & & 1.353 & 0.337 \\
\hline Increase & $8(23.5 \%)$ & 7(38.9\%) & & \\
\hline Decrease & $26(76.5 \%)$ & $11(61.1 \%)$ & & \\
\hline Gender & & & 8.497 & 0.008 \\
\hline Male & $12(35.3 \%)$ & 14(77.8\%) & & \\
\hline Female & $22(64.7 \%)$ & $4(22.2 \%)$ & & \\
\hline Age & & & 3.059 & 0.072 \\
\hline$\geq 62.5$ & $14(41.2 \%)$ & 12(66.7\%) & & \\
\hline$<62.5$ & $20(58.8 \%)$ & 6(33.3\%) & & \\
\hline Smoking & & & 6.540 & 0.013 \\
\hline Past/current & $27(79.4 \%)$ & $8(44.4 \%)$ & & \\
\hline Never & $7(20.6 \%)$ & 10(55.6\%) & & \\
\hline Exon 21 & & & 0.575 & 0.519 \\
\hline No & $26(76.5 \%)$ & 12(66.7\%) & & \\
\hline Yes & $8(23.5 \%)$ & 6(33.3\%) & & \\
\hline Exon 19 & & & 0.001 & 0.605 \\
\hline No & 19(55.9\%) & 10(55.6\%) & & \\
\hline Yes & $15(44.1 \%)$ & $8(44.4 \%)$ & & \\
\hline Other diseases & & & 5.967 & 0.016 \\
\hline No & $25(73.5 \%)$ & 7(38.9\%) & & \\
\hline Yes & $9(26.5 \%)$ & $11(61.1 \%)$ & & \\
\hline Other treatment & & & 1.549 & 0.172 \\
\hline No & $11(32.4 \%)$ & $9(50 \%)$ & & \\
\hline Yes & $23(67.6 \%)$ & $9(50 \%)$ & & \\
\hline
\end{tabular}

OS overall survival, OS (-) survival group, OS (+) death group

Thus, the overt or cryptic abnormalities of coagulation parameters are detected in about 50\% cancer patients as well as $90 \%$ with metastatic diseases [16-18].

TF is suggested in recent study to trans-activate EGFR and regulate gene expression $[19,20]$. Typically, the TFinduced EGFR activation is closely correlated with the procoagulant activity of cancer cells, which is achieved through the Nuclear transcription factor activates protein-1 (AP-1) transcriptional activation [21]. Under such situations, TF binds to FVIIa, an enzyme active form of FVII, and triggers the production of other coagulation-related proteases, such as FXa and FIXa. Of them, FXa cooperates with FVa to cleave the circulating prothrombin for evoking the thrombin (FIIa) activity, which is required for activating platelets. Besides, it can 
Table 5 Univariate and multivariate Cox analysis of PFS among patients who received EGFR-TKI treatment

\begin{tabular}{|c|c|c|c|c|c|c|}
\hline & \multicolumn{3}{|c|}{ Univariate analysis } & \multicolumn{3}{|c|}{ Multivariate analysis } \\
\hline & $\mathrm{HR}$ & $95 \% \mathrm{Cl}$ & $P$ & $\mathrm{HR}$ & $95 \% \mathrm{Cl}$ & $P$ \\
\hline \multicolumn{7}{|l|}{ Platelet } \\
\hline (Decrease VS Increase) & 0.592 & $0.325-1.080$ & 0.087 & & & \\
\hline \multicolumn{7}{|l|}{ D-dimer } \\
\hline (Decrease VS Increase) & 0.733 & $0.387-1.391$ & 0.342 & & & \\
\hline Male VS Female & 0.728 & $0.399-1.326$ & 0.299 & & & \\
\hline Age ( $\geq 62.5$ vs. others) & 1.104 & $0.617-1.976$ & 0.738 & & & \\
\hline \multicolumn{7}{|l|}{ Substitution in exon 21} \\
\hline (Yes vs. No) & 0.934 & $0.489-1.787$ & 0.837 & & & \\
\hline \multicolumn{7}{|l|}{ Deletion in exon 19} \\
\hline (Yes vs. No) & 1.392 & $0.774-2.502$ & 0.269 & & & \\
\hline Smoking(Yes vs. No) & 1.360 & $0.728-2.539$ & 0.335 & & & \\
\hline \multicolumn{7}{|l|}{ Other treatment } \\
\hline (Yes vs. No) & 0.691 & $0.377-1.266$ & 0.231 & & & \\
\hline \multicolumn{7}{|l|}{ Other diseases } \\
\hline (Yes vs. No) & 1.254 & $0.695-2.263$ & 0.452 & & & \\
\hline
\end{tabular}

PFS progression-free survival, $H R$ hazard ratio

set off the amplification phase of the hemostatic process through generating several active clotting factors, including FVIIIa and FXIa [22]. Even in the asymptomatic cases, coagulopathy can be inferred from laboratory findings, which is possibly accompanied with chronically activated coagulation, like the increased levels of circulating FVIIa, prothrombin fragment $1+2$, and fibrinopeptides A and B, together with the altered (increased or decreased) platelet count [23].

Tumour metastasis is dependent on the interactions between tumour cells and the host circulatory microenvironments, such as the lymphatic vessels and targeted tissues; moreover, the platelet levels also support tumor metastasis [24]. At the molecular biology level, the

Table 6 Univariate and multivariate Cox analysis of OS among patients who received EGFR-TKI treatment

\begin{tabular}{|c|c|c|c|c|c|c|}
\hline & \multicolumn{3}{|c|}{ Univariate analysis } & \multicolumn{3}{|c|}{ Multivariate analysis } \\
\hline & $\mathrm{HR}$ & $95 \% \mathrm{Cl}$ & $P$ & HR & $95 \% \mathrm{Cl}$ & $P$ \\
\hline \multicolumn{7}{|l|}{ Platelet } \\
\hline (Decrease VS Increase) & 0.311 & $0.118-0.818$ & 0.018 & 0.293 & $0.107-0.799$ & 0.017 \\
\hline \multicolumn{7}{|l|}{ D-dimer } \\
\hline (Decrease VS Increase) & 0.538 & $0.204-1.416$ & 0.209 & & & \\
\hline Male VS Female & 0.207 & $0.059-0.724$ & 0.014 & 0.195 & $0.042-0.914$ & 0.038 \\
\hline Age ( $\geq 62.5$ vs. others) & 1.937 & $0.716-5.240$ & 0.193 & & & \\
\hline \multicolumn{7}{|l|}{ Substitution in exon 21} \\
\hline (Yes vs. No) & 1.008 & $0.355-2.867$ & 0.988 & & & \\
\hline \multicolumn{7}{|l|}{ Deletion in exon 19} \\
\hline (Yes vs. No) & 1.150 & $0.443-2.987$ & 0.774 & & & \\
\hline Smoking(Yes vs. No) & 2.931 & $1.112-7.730$ & 0.030 & 0.695 & $0.199-2.422$ & 0.568 \\
\hline \multicolumn{7}{|l|}{ Other treatment } \\
\hline (Yes vs. No) & 0.500 & $0.192-1.300$ & 0.155 & & & \\
\hline \multicolumn{7}{|l|}{ Other diseases } \\
\hline (Yes vs. No) & 2.92 & $1.079-7.901$ & 0.035 & 2.796 & 0.970-8.059 & 0.057 \\
\hline
\end{tabular}




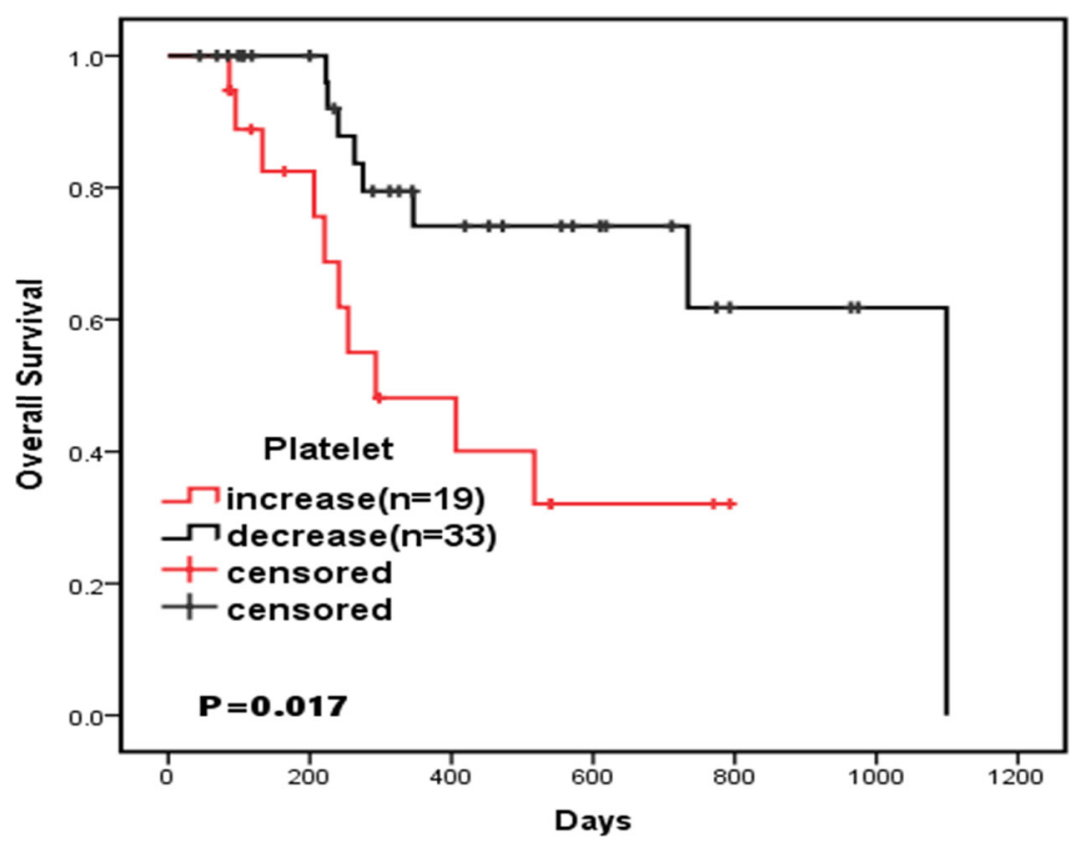

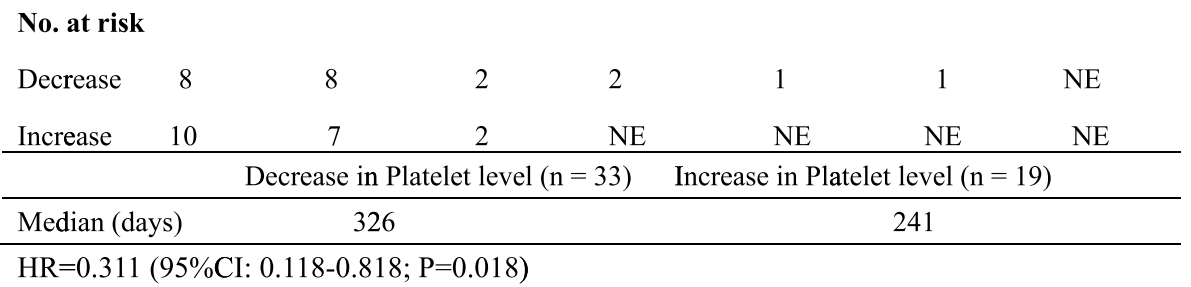

Fig. 1 Kaplan-Meier-estimated OS on stratifying by the platelet count \{decrease $(N=33)$ vs. increase $(N=19)\}$

malignant grade of tumor is associated with the levels of platelets and cytokines, for example, the VEGF, plateletderived growth factor (PDGF), transforming growth factor $\beta$ (TGF- $\beta$ ), and interleukin 6 (IL-6) [25]. Lim et al. demonstrated in their study that, the ratio of platelet combined with lymphocyte to monocyte might be adopted to predict the short survival for stage IV NSCL $\mathrm{C}$ patients [26]. In general, platelets are known to be upregulated among lung cancer patients, and the high platelet count may imply the dismal prognosis [12]. Therefore, the current retrospective study was carried out to determine whether the decreased platelet count among lung cancer patients predicted the efficacy of EGFR-TKI treatment. According to our results, the EGFR-TKI treatment exhibited positive prognostic effect, along with the decreased platelet count (Table 2 and Fig. 1). It seemed that, such treatment indicated a novel approach for future studies concerning the anticancer biomarkers, including the anti-EGFR treatment.

Interestingly, the circulating platelets containing hepatocyte growth factor (HGF) and TGF- $\beta$ may induce resistance to EGFR-TKIs, which is achieved through activating the bypass signaling pathway or the epithelial to mesenchymal transition (EMT) [27-30]. Miyata K et al. demonstrated that PDGF activated EGFR [31]. EGF is the only growth factor that is reported as the EGFR ligand in platelets [24]. EGF can directly control tumor disease and anticancer therapy by restoring the balance between prothrombotic and fibrinolytic processes.

Moreover, some existing data show that, the longer PFS is not correlated with the longer OS among cancer patients who receive targeted drug therapy, like the antiEGFR therapy [32]. On this account, our findings had definite clinical values, since the same results were found. During the treatment, OS were markedly prolonged with the decrease in platelet count. However, the change in PFS was not obvious (Tables 3 and 5). Perhaps the association between decreased platelet count and PFS can be more fully analyzed as the sample size increases.

It is suggested in some study that, a pathogenic feedback loop may be operative between platelets and tumor cells, along with the reciprocal interactions between tumor growth/metastasis and thrombocytosis/platelet activation. Specific molecular pathways have been identified, in which tumors can stimulate the production and 


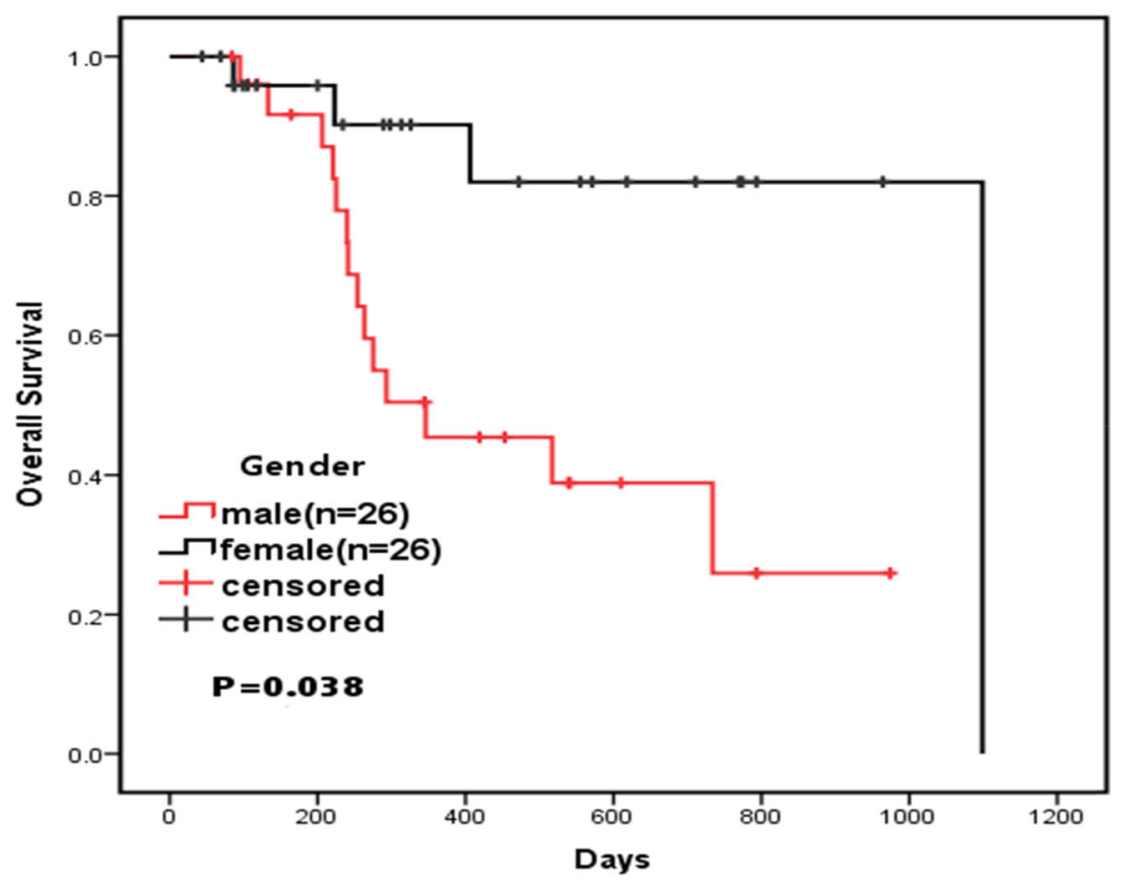

No. at risk

\begin{tabular}{lccccccc} 
Male & 14 & 12 & 2 & 1 & NE & NE & NE \\
Female & 4 & 3 & 2 & 1 & 1 & 1 & NE \\
\hline \multicolumn{3}{c}{ Male $(\mathrm{n}=26)$} \\
\hline \multicolumn{3}{c}{305.5} \\
\hline Median(days)
\end{tabular}

Fig. 2 Kaplan-Meier-estimated OS on stratifying by gender $\{$ male $(N=26)$ vs. female $(N=26)\}$

activation of platelets, and this in turn will promote tumor growth and metastasis [12]. Based on certain clinical data, aspirin has been used to evaluate the effect of anti-platelet agents on cancer survival [6]. Specifically, a recent large, randomized cardiovascular prevention trial shows that, cancer patients with sufficient aspirin administration are associated with lower risks of cancer metastasis, which is achieved through inhibiting the platelet function [33]. Antiplatelet therapy combined with conventional targeted antitumor therapy should be considered in the future, even though its efficacy has not been unequivocally proven yet.

In addition, our study showed that the OS of male patients receiving EGFR-TKIS was relatively longer (Fig. 2). However, previous studies have shown that PFS and OS of females are longer than that of men [34], and more studies have found that gender has no correlation with PFS and OS $[35,36]$. Therefore, it may be the insufficient sample size that leads to the deviation of results, which requires further research.
Some limitations should be noted in this study. Firstly, this was a retrospective study with a small sample size; Therefore, a prospective study with a greater sample size is required to validate our results. Secondly, the high censoring rate at the end of the follow-up had hampered the accurate estimation of OS. Thirdly, because the sample size was insufficient and the final outcome of lung cancer patients was progression, selection deviation was caused, which may have affected the results of the study on the correlation between platelet count and PFS.

\section{Conclusions}

Our findings suggest that, the decreased platelet count seems to serve as a significant predictor for OS among NSCLC patients receiving EGFR-TKIs. Changes in platelet count may serve as a meaningful parameter to establish the prognostic model for patients receiving targeted therapy. Our results reveal a novel underlying mechanism of adjuvant therapy associated with the functional status of platelets. 


\section{Abbreviations}

NSCLC: Non-small cell lung cancer; EGFR: Epidermal growth factor receptor; EGFR-TKIs: Epidermal Growth Factor Receptor tyrosine kinase inhibitors; PFS: Progression-free survival; OS: Overall survival; TE: Thromboembolism; VTE: Venous thromboembolism; HR: Hazard ratio; DVT: Deep vein thrombosis; PE: Pulmonary embolism, VEGF: Vascular endothelial growth factor; microRNA: Non-coding RNA; DIC: Disseminated intravascular coagulation; MET: Methionine; PRMs: Platelet-released molecules; RAS: Renin-angiotensin system; PAR: Protease activated receptors; ALT: Alanine aminotransferase; AST: Aspartate aminotransferase; CT: Computed Tomography; RECI ST: Response Evaluation Criteria in Solid Tumors; AP-1: Nuclear transcription factor activates protein-1; PDGF: Platelet-derived growth factor; IL6: Interleukin 6; TGF- $\beta$ : Transforming growth factor $\beta$; EMT: Mesenchymal transition; HGF: Hepatocyte growth factor

\section{Acknowledgements}

None.

\section{Authors' contributions}

Study design: LX, FZX, YZY and YBZ; Data extraction: LX, FZX, HBK and MLZ; Data analysis: LX, FZX, HBK and MLZ; Manuscript writing: LX and FZX; Manuscript edition: YBZ and YZY. All authors have read and approved the manuscript.

\section{Funding}

The present study was supported by the Natural Science Foundation of Anhui Province (Anhui, China) (Grant Number: KJ2018A0208). The funding body has no role in the design of the study and collection, analysis, and interpretation of data and in writing the manuscript.

\section{Availability of data and materials}

The datasets generated and/or analyzed during the current study are not publicly available due owing to data privacy policy at our facility, but are available from the corresponding author on reasonable request.

\section{Ethics approval and consent to participate}

The study protocol was approved by the Medical Ethics and Human Clinical Trial Committee of The First Affiliated Hospital of Anhui Medical University. Given that this study was a retrospective study and all data were collected retrospectively from electronic medical records, informed consent is waived. But we did guarantee the opportunity by opt-out. Obtaining consent in this way was approved by the ethics committee of The First Affiliated Hospital of Anhui Medical University. All procedures performed in studies involving human participants were in accordance with the ethical standards of the national research committee and with the 1964 Helsinki declaration and its later amendments or comparable ethical standards. Administrative permissions were acquired by our team to access the data used in this research.

\section{Consent for publication}

Not applicable.

\section{Competing interests}

The authors declare that they have no competing interests.

Received: 12 April 2020 Accepted: 17 November 2020

Published online: 26 November 2020

\section{References}

1. Khorana AA, Francis CW, Culakova E, Kuderer NM, Lyman GH. Thromboembolism is a leading cause of death in cancer patients receiving outpatient chemotherapy. J Thromb Haemost. 2007;5:632-4.

2. Rak J. Ras oncogenes and tumour vascular interface. In: Thomas-Tikhonenko A, editor. Cancer genome and tumor microenvironment, springer; 2009. p. 133-65.

3. Rickles FR. Mechanisms of cancer-induced thrombosis in cancer. Pathophysiol Haemost Thromb. 2006;35(1-2):103-10.

4. Kanaji N, Mizoguchi $H$, Inoue $T$, et al. Clinical features of patients with lung cancer accompanied by thromboembolism or disseminated intravascular coagulation. Therapeutics and clinical risk management. Ther Clin Risk Manag. 2018;14:1361-8.
5. Wijten $\mathrm{P}$, Van Holten $\mathrm{T}$, Woo LL, et al. High precision platelet releasate definition by quantitative reversed protein profiling-brief report. Arterioscler Thromb Vasc Biol. 2013;33(7):1635-8.

6. Bambace NM, Holmes CE. The platelet contribution to cancer progression. J Thromb Haemost. 2011;9(2):237-49.

7. Tawil N, Chennakrishnaiah S, Bassawon R, Johnson R, D'Asti E, Rak J. Single cell coagulomes as constituents of the oncogene-driven coagulant phenotype in brain tumours. Thromb Res. 2018;164(Suppl 1):S136-42.

8. Rak J, Yu JL, Luyendyk J, Mackman N. Oncogenes, trousseau syndrome, and Cancer-related changes in the Coagulome of mice and humans. Cancer Res. 2006;66(22):10643-6.

9. Kalia M. Personalized oncology: recent advances and future challenges. Metabolism. 2013;62(Suppl 1):S11-4.

10. Li T, Kung HJ, Mack PC, Gandara DR. Genotyping and genomic profiling of nonsmall-cell lung cancer: implications for current and future therapies. J Clin Oncol. 2013;31(8):1039-49.

11. Aoe $\mathrm{K}$, Hiraki A, Ueoka H, et al. Thrombocytosis as a useful prognostic indicator in patients with lung cancer. Respiration. 2004;71(2):170-3.

12. Lin RJ, Afshar-Kharghan V, Schafer Al. Paraneoplastic thrombocytosis: the secrets of tumor selfpromotion. Blood. 2014;124(2):184-7.

13. Soria JC, Ohe Y, Vansteenkiste J, et al. Osimertinib in untreated EGFR-mutated advanced non-small-cell lung Cancer. N Engl J Med. 2018;378(2):113-25.

14. Yang JC, Ahn MJ, Kim DW, et al. Osimertinib in pretreated T790M-positive advanced non-small-cell lung Cancer: AURA study phase II extension component. J Clin Oncol. 2017;35(12):1288-96.

15. Farge $D$, Debourdeau $P$, Beckers $M$, et al. International clinical practice guidelines for the treatment and prophylaxis of venous thromboembolism in patients with cancer. J Thromb Haemost. 2013;11(1):56-70.

16. Rickles FR, Patierno S, Fernandez PM. Tissue factor, thrombin, and cancer. Chest. 2003;124(3 Suppl):58S-68S

17. Nand S, Messmore H. Hemostasis in malignancy. Am J Hematol. 1990;35(1):45-55.

18. Wojtukiewicz MZ, Sierko E, Klement P, Rak J. The hemostatic system and angiogenesis in malignancy. Neoplasia. 2001;3(5):371-84.

19. Wiiger MT, Prydz H. The epidermal growth factor receptor (EGFR) and proline rich tyrosine kinase 2 (PYK2) are involved in tissue factor dependent factor Vlla signalling in HaCaT cells. Thromb Haemost. 2004;92(1):13-22.

20. Magnus N, Garnier D, Rak J. Oncogenic epidermal growth factor receptor up-regulates multiple elements of the tissue factor signaling pathway in human glioma cells. Blood. 2010;116(5):815-8.

21. Rong Y, Belozerov VE, Tucker-Burden C, et al. Epidermal growth factor receptor and PTEN modulate tissue factor expression in glioblastoma through JunD/ activator protein-1 transcriptional activity. Cancer Res. 2009;69(6):2540-9.

22. Morrissey JH. Tissue factor: an enzyme cofactor and a true receptor. Thromb Haemost. 2001;86(1):66-74.

23. Falanga A. Thrombophilia in cancer. Semin Thromb Hemost. 2005;31(1):104-10.

24. Gay LJ, Felding-Habermann B. Contribution of platelets to tumour metastasis. Nat Rev Cancer. 2011;11(2):123-34.

25. Verheul HM, Hoekman K, Luykx-de Bakker S, et al. Platelet: transporter of vascular endothelial growth factor. Clin Cancer Res. 1997;3(12 Pt 1):2187-90.

26. Lim JU, Yeo CD, Kang HS, et al. Prognostic value of platelet count and lymphocyte to monocyte ratio combination in stage IV non-small cell lung cancer with malignant pleural effusion. PLoS One. 2018;13(7):e0200341.

27. Nakamura T, Teramoto $H$, Ichihara A. Purification and characterization of a growth factor from rat platelets for mature parenchymal hepatocytes in primary cultures. Proc Natl Acad Sci U S A. 1986;83(17):6489-93.

28. Assoian RK, Sporn MB. Type beta transforming growth factor in human platelets: release during platelet degranulation and action on vascular smooth muscle cells. J Cell Biol. 1986;102(4):1217-23.

29. Yano $S$, Wang $W, L i$, et al. Hepatocyte growth factor induces gefitinib resistance of lung adenocarcinoma with epidermal growth factor receptoractivating mutations. Cancer Res. 2008;68(22):9479-87.

30. Suda K, Tomizawa K, Fujii M, et al. Epithelial to mesenchymal transition in an epidermal growth factor receptor-mutant lung cancer cell line with acquired resistance to erlotinib. J Thorac Oncol. 2011;6(7):1152-61.

31. Miyata K, Takemoto A, Okumura S, Nishio M, Fujita N. Podoplanin enhances lung cancer cell growth in vivo by inducing platelet aggregation. Sci Rep. 2017;7(1):4059.

32. Greenhalgh J, Dwan K, Boland A, et al. First-line treatment of advanced epidermal growth factor receptor (EGFR) mutation positive non-squamous non-small cell lung cancer. Cochrane Database Syst Rev. 2016;(5):CD010383. https://doi.org/10.1002/14651858.CD010383.pub2. 
33. Rothwell PM, Wilson M, Price JF, Belch JF, Meade TW, Mehta Z. Effect of daily aspirin on risk of cancer metastasis: a study of incident cancers during randomised controlled trials. Lancet. 2012;379(9826):1591-601.

34. Jiang $H$, Zhu M, Li Y, Li Q. Association between EGFR exon 19 or exon 21 mutations and survival rates after first-line EGFR-TKI treatment in patients with non-small cell lung cancer. Mol Clin Oncol. 2019;11(3):301-8.

35. Yu JY, Yu SF, Wang SH, et al. Clinical outcomes of EGFR-TKI treatment and genetic heterogeneity in lung adenocarcinoma patients with EGFR mutations on exons 19 and 21. Chin J Cancer. 2016;35:30.

36. Lin $J H$, Lin $D, X u L$, et al. The association between clinical prognostic factors and epidermal growth factor receptor-tyrosine kinase inhibitor (EGFR-TKI) efficacy in advanced non-small-cell lung cancer patients: a retrospective assessment of 94 cases with EGFR mutations. Oncotarget. 2017;8(2):3412-21.

\section{Publisher's Note}

Springer Nature remains neutral with regard to jurisdictional claims in published maps and institutional affiliations.

Ready to submit your research? Choose BMC and benefit from:

- fast, convenient online submission

- thorough peer review by experienced researchers in your field

- rapid publication on acceptance

- support for research data, including large and complex data types

- gold Open Access which fosters wider collaboration and increased citations

- maximum visibility for your research: over $100 \mathrm{M}$ website views per year

At $\mathrm{BMC}$, research is always in progress.

Learn more biomedcentral.com/submissions 